\title{
Do roads lead to grassland degradation or restoration? A case study in Inner Mongolia, China
}

\author{
XIANGZHENG DENG
}

Center for Chinese Agricultural Policy, Institute of Geographic Sciences

and Natural Resource Research, Chinese Academy of Sciences, No. 11A Datun Road, Chaoyang, Beijing, 100101, China.

Email:dengxz.ccap@igsnrr.ac.cn

\section{JIKUN HUANG}

Center for Chinese Agricultural Policy, Institute of Geographic Sciences and Natural Resource Research, Chinese Academy of Sciences, China.

Email: jkhuang.ccap@igsnrr.ac.cn

\section{QIUQIONG HUANG}

Department of Applied Economics, University of Minnesota, USA.

Email: qhuang@umn.edu

\section{SCOTT ROZELLE}

Freeman Spogli Institute, Stanford University, USA.

Email: rozelle@stanford.edu

\section{JOHN GIBSON}

Department of Economics, University of Waikato, New Zealand.

Email: jkgibson@mngt.waikato.ac.nz

Submitted April 28, 2010; revised December 14, 2010; accepted April 25, 2011

\begin{abstract}
We use satellite remote sensing data of grassland cover in Inner Mongolia, China to test whether the existence of and the size of roads in 1995 is associated with the nature of the grassland in 2000 and/or if it affects the rate of change of

This research was supported by the National Key Programme for Developing Basic Science (2010CB950904), the National Scientific Foundation of China (70873118, 40801231, 41071343) and the Ministry of Science and Technology of China (2008BAC43B01, 2008BAK50B06, 2008BAC44B04). Data support from the data interpretation team led by Jiyuan Liu is greatly appreciated.
\end{abstract}


2 Xiangzheng Deng et al.

the grassland between 1995 and 2000. The regression results show that the impact of roads on grassland cover depends on the nature of the resource. When the grassland is composed of relatively high quality grassland, roads lead to degradation, whereas when grassland resources are sparse, access to a road results in the restoration of the resource.

\section{Introduction}

With the enormous global concerns about climate change and biodiversity in recent years (Jenkins et al., 1990; Magurran, 2004), grassland has received more attention than ever before as a type of natural resource that plays an important role in sequestrating carbon (Conant et al., 2001) and preserving biodiversity (Tilman and Downing, 1994). Inside China, concerns over the severe environmental consequences of grassland degradation, such as sandstorms and desertification, have stimulated a large literature on understanding the factors leading to degradation. These factors include overgrazing, population pressure, urbanization, conversion to crop land and climatic factors (Smil, 1993; Gong et al., 2000; Zhang et al., 2006; Akiyama and Kawamura, 2007; Liu et al., 2008).

At the same time, in the rapidly growing literature on deforestation, roads are identified as one of the important determinants. In many instances roads are found to exacerbate the rate of deforestation (e.g., Chomitz and Gray, 1996; Mertens and Lambin, 1997; Pfaff, 1999; Cropper et al., 2001). When new roads are constructed or when existing roads are widened or paved, the access to forested area is less costly. Furthermore, by lowering transport costs, roads also increase the value of agricultural products, accelerating the clearing of forested areas for agriculture. However, in a few studies, the opposite impacts are identified. Andersen et al. (2002) find that new roads reduce the rate of deforestation in the Brazilian Amazon, at least in counties with substantial prior clearing of forest. The suggested causal mechanism is that roads provide a focal point for local development, drawing pressure away from the forested hinterland. Similarly, Deininger and Minten (2002) find that roads weaken the negative impact on forests of high poverty levels in Southern Mexico.

In the grassland literature, only a small group of studies have focused on the relationship between roads and grassland degradation. Mostly the ecological effects of roads on the grassland ecosystem are considered (White et al., 2000; $\mathrm{Wu}$ and $\mathrm{Ci}, 2002)$. For example, the construction of roads separates formerly integrated ecosystems into separate and ecologically more vulnerable parts. Road traffic significantly reduces the regular breeding activities of several species of grassland birds (Forman et al., 2002). Roads have also been shown to increase the possibility of the invasion of non-native species (Forman, 2000).

A smaller number of studies focus on the non-ecological impacts of roads on the grassland. For example, in the suburbs of Melbourne, the probability of a patch of grassland being destroyed increases for patches closer to a major road, since the completion of the road triggers economic development in suburban areas (Williams et al., 2005). In a case study from Colombia it was found that, because of increased stocking rates near roads, pasture 
was so damaged by trampling that it was not able to take advantage of the relatively high levels of fertility of the soil (Conant et al., 2001). Inside China, Gao et al. (2007) show that human activity in the region near to the roads of North Tibet had a negative effect on the grasslands. The common finding in these papers is that roads led to grassland degradation. The logic of these authors is that, when there are roads in a specific area (or when a road is widened or improved), pressure will rise on the grassland resources as it becomes easier to access and/or more profitable to exploit the value that is associated with the grassland resource. Hence, it is predicted that roads will make the grassland cover fall.

On the other hand, some authors find that roads do not necessarily lead to grassland destruction (Zhang et al., 2002; Williams et al., 2006). Instead the impact of roads on grasslands depends on the type of road and the type of grassland. In a case study from the source region of China's Yellow River, Zhang et al. (2006) find roads not to have a negative impact on grassland. Gao et al. (2007) also find that, although grasslands have shown clear signs of degradation in some of the high elevation regions of Northern Tibet, in other areas (especially in those areas in which human activity is relatively intense), roads have actually led to higher quality grassland resources. These authors postulate that better road access allows for more successful implementation of grassland restoration projects. The implicit logic of these papers is that, when a road enters an area, it allows agents access to new resources from outside the grassland which may actually reduce pressure on (or increase investment for restoration in) the local economy's grassland resource base.

A consensus is yet to form, however, because in addition to the paucity of studies on grasslands and roads, inadequate data and methodological shortcomings weaken some findings in this literature. For example, many studies (e.g., Zhang et al., 2002; Gao et al., 2007) only look at the relationship between roads and the grasslands without controlling for other covariates, while others (for example, Liu et al., 2008), include only a single control variable. Moreover, only one paper to our knowledge - Williams (2007) conducted case studies using time variant variables; most other studies do not follow the quantity or quality of the grassland resources over time.

Since the existing evidence on the effect of roads on grassland is ambiguous and has not always benefited from the latest refinements in data and methodology, new evidence is required. Specifically, in this paper we use satellite remote sensing images of grassland cover in Inner Mongolia, China to test whether the existence of and the size of roads (ranging from expressways to tertiary roads) in 1995 affected the level of grassland cover in 2000 or the rate of grassland change between 1995 and 2000. Our overall goal is to discover if roads are leading to grassland degradation or grassland restoration or if they are neutral. The focus of our empirical work is on the relatively grassland rich area in the middle region of Inner Mongolia.

To meet these objectives, the paper has four sections. In the first section we describe the data and define the key variables in our analysis. The second section lays out the econometric approach that we use to explore in greater depth the relationship between roads and grassland degradation. The third section reports the results of the estimation and discusses the findings. The final section concludes. 
4 Xiangzheng Deng et al.

While this paper is ambitious in its objectives, it has certain limitations. Above all, although we are interested ultimately in the impact of roads on the grassland environment and the services grassland provides, this paper is focused on grassland degradation. In other words, we do not examine the effect of roads on the ecological services provided by grassland per se. In particular, grassland has received more attention than ever as a type of natural resource that plays an important role in sequestrating carbon (Conant et al., 2001) and preserving biodiversity (Tilman and Downing, 1994). It is clear that these elements and the ecosystem services they provide are closely related to grassland degradation.

\section{Data, definitions and simple descriptive relationships}

In our study we use a land use database developed by the Chinese Academy of Sciences (CAS) with original data from Landsat Thematic Mapper/Enhanced Thematic Mapper (Plus)(TM/ETM+) images which have a spatial resolution of $30 \times 30 \mathrm{~m}$ (see Supplementary appendix 1 online). These high quality satellite remote sensing digital images have been aggregated by CAS into $1 \times 1 \mathrm{~km}$ picture elements ('pixels') which are the observations used in this study (Deng et al., 2006). The database includes observations for two time periods: (a) the mid-1990s, including Landsat TM/ETM+ scenes from 1995 and 1996 (henceforth, 1995); and (b) the later 1990s, including Landsat TM/ETM+ scenes from 1999 and 2000 (henceforth, 2000). ${ }^{1}$ For each time period more than $500 \mathrm{TM} / \mathrm{ETM}+$ scenes were used to cover the entire country. The data team also spent considerable time and effort in validating the interpretation of TM/ETM+ images and land cover classifications against extensive field surveys (Liu et al., 2003; Deng et al., 2008a). ${ }^{2}$ A hierarchical classification system of 25 land use classes was originally applied to the data, which can be aggregated into six classes of land cover: cultivated land, forestry area, grassland, water area, built-up area, and unused land. In this study we focus on the specific land use types under the category of grassland.

The high quality of the satellite remote sensing imagery allows us to subdivide the grasslands into three quality categories. The first type of grassland, the highest quality grassland with canopy cover that exceeds 50 per cent, is categorized as dense canopy grassland (or Dense grassland). The second type of grassland (with a canopy covering 20-50 per cent of the land) is categorized as moderate canopy grassland (or Moderate grassland). The third type of grassland, sparse canopy grassland (Sparse grassland), has a canopy

${ }^{1}$ A small share of TM/ETM+ digital images (less than 4 per cent of the total) were not available during 1995 because of clouds. Replacements were drawn from a database of 1996 images. The same was true for 2000 (most were from 2000; only a small share were from 1999).

${ }^{2}$ A TM/ETM+ scene is the unit of area of coverage of digital images that are made by Landsat satellites. In the original Landsat material, which was configured by NASA before they provided the material to CAS, it took about 500 scenes to completely cover all of China's territory. Additional details about the methodology which we used to generate the databases of land cover from Landsat TM/ETM+ are documented in Liu et al. (2002). 
covering 5-20 per cent of the land. If the canopy cover is less than 5 per cent, it is not counted as grassland.

In order to create an aggregated variable that captures the inter- and intrapixel differences in the quality of the grassland, we can use our data to create a single quality-adjusted measure of grassland area (QA-Grassland). This is done by multiplying the fraction of each pixel that is in each type of grassland (Dense, Moderate and Sparse) by a weight representing the median canopy cover in each category of grassland. ${ }^{3}$ The formula for calculating the $Q A-G$ rassland is:

$$
\begin{aligned}
Q A-G r a s s l a n d= & w^{d} \cdot(\text { Dense grassland area })+w^{m} \cdot(\text { Moderate grassland area }) \\
& +w^{s} \cdot(\text { Sparse grassland area })
\end{aligned}
$$

where $w^{d}=0.75$ is for Dense grassland, $w^{m}=0.35$ is for Moderate grassland, and $w^{s}=0.125$ is for Sparse grassland (these are the mid-points of canopy coverage for each category).

\subsection{The choice of study area}

Mapping the grassland resources of China illustrates why we need to narrow the focus of our study. According to satellite imagery from all of China, there are more than $4,000,000 \mathrm{~km}^{2}$ of grasslands, covering above 40 per cent of the nation's total area. Using all of these data would mean working with at least 4,000,000 observations, which would be computationally burdensome. Therefore we restrict our attention to the case of Inner Mongolia (figure 1). With the exception of the more remote areas of China's far west, the grasslands in Inner Mongolia are the most abundant in China. Inner Mongolia's grasslands account for 18 per cent of China's total grassland area. They also are by far the most economically important grasslands in China; much of the area in Tibet and Xinjiang is not used for raising livestock and population densities are low. Within Inner Mongolia, the area covered by grasslands accounts for 31 per cent of the total area.

However, even if we just restricted our attention to this one province, we would still have to deal with a large (potentially unwieldy) sample of more than 1,000,000 observations (the total area of the province is $1,143,314 \mathrm{~km}^{2}$ ). Because of this, we decided to restrict our attention further to a specific region of Inner Mongolia. Traditionally, the province can be broken into

${ }^{3}$ The weights in equation (1) are made in order to produce an aggregated variable that captures the inter- and intra-pixel differences in the quality of the grassland. To produce such a measure (QA-Grassland) we multiply the fraction of each pixel that is in each type of grassland (Dense, Moderate and Sparse) by a weight that represents the average canopy cover of each type of grassland. What is the weight? Recall the first type of grassland: the highest quality grassland with canopy cover that exceeds 50 per cent is categorized as Dense grassland. This means that the density of dense canopy grassland is between 50 and 100. The average of 50 and 100 is 0.75 , which is precisely the weight used in equation (1) for Dense grassland. The second type of grassland (with a canopy covering 2050 per cent of the land) is categorized as Moderate grassland. Its weight is the average of 20 and 50 or 0.35 . The third type of grassland, Sparse grassland, has a canopy covering 5-20 per cent of the land (which means the weight is 0.125 ). 
A

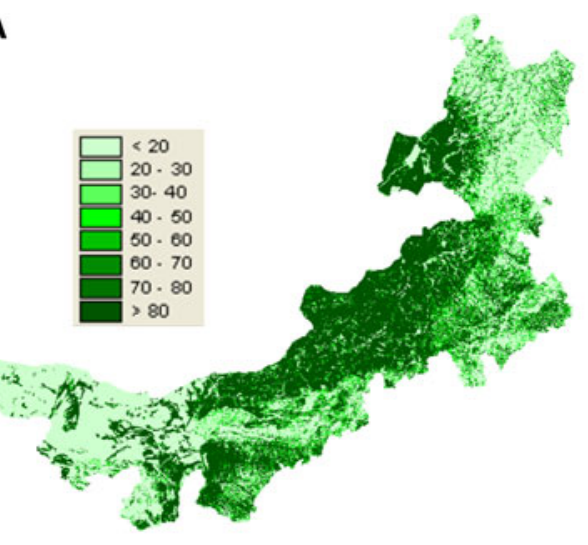

1995

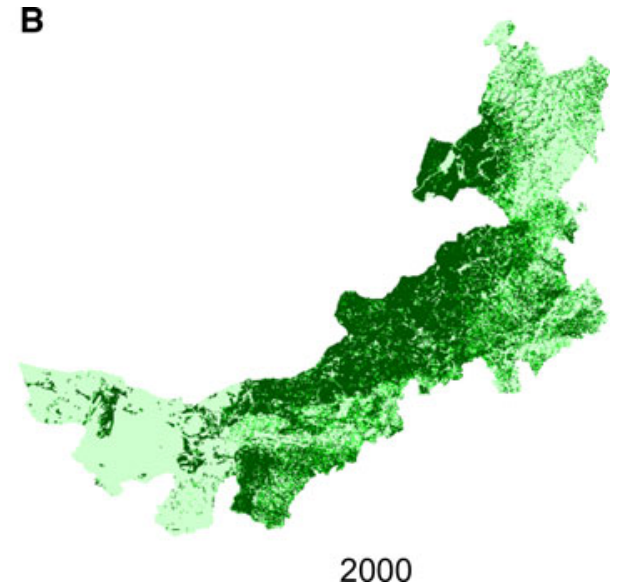

2000

Figure 1. Grassland cover in (a) 1995 and (b) 2000 in Inner Mongolia.

three regions - the western zone, the middle zone and the eastern zone (figure 2; China Agricultural Zoning Committee (1989)). Since the western zone, which is mostly desert, contains less than 10 per cent of the province's grassland (see Supplementary appendix 2, table A1, row 4 online), and the eastern zone, which traditionally was part of the northeastern agricultural belt (that is, it is in many respects more like Heilongjiang and Jilin provinces than the rest of Inner Mongolia), only contains about 20 per cent of the province's grassland (see Supplementary appendix 2, table A1, row 3 online), we decided to focus on the middle zone. It should be noted that within the middle grassland region in 1995, 50.4 per cent of the grassland is Dense grassland cover, 36.4 per cent of the grassland is Moderate grassland cover, and 13.2 per cent of the grassland is Sparse grassland cover.

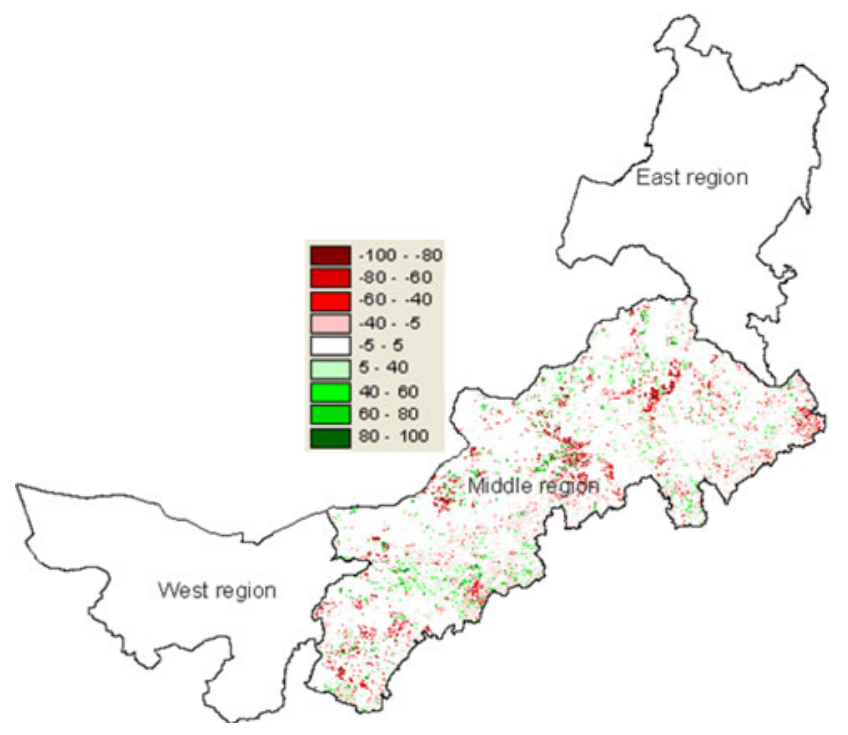

Figure 2. Spatial heterogeneity in the changes in grassland cover in each $1 \mathrm{~km}^{2}$ in the Middle Grassland Zone of Inner Mongolia in the period between 1995 and 2000. 


\subsection{Data for explanatory variables: roads and other factors}

The basic data for our roads variable come from provincial, county and local maps from the CAS data center. The maps are up to date through 1995. The information from hard copies of the maps was digitized by a CAS working group in 1999 and 2000. Although it would be simple to calculate the straight-line distance from each pixel to the nearest segment of digitized road, such an approach is likely to provide a misleading measure of road access. More than half of Inner Mongolia's land area is grassland growing on rolling hills that are punctuated by gullies, valleys and canyons. In such an environment, a realistic measure of accessibility requires knowledge of the topography and, in particular, of watersheds. Our assumption is that travel within a watershed is likely to be less impeded than travel between watersheds. Hence, if a road enters a watershed, all pixels within that watershed are likely to have relatively easier access to the road. ${ }^{4}$

A second issue also arises concerning what is the appropriate unit into which we should divide our data. Should we use administrative boundaries such as counties, or should we use natural boundaries such as watersheds? It is plausible that settlement and grazing decisions are influenced by grass quality (or some other cross-watershed policy or economic force) at a larger scale than the pixel level. Planning of large roads is also likely to occur at a much larger scale than the pixel. There are also many other factors that suggest that natural watershed boundaries are more appropriate than administrative boundaries. This is especially true considering that the boundaries of watersheds reflect the inherent winding line of a watershed in which all the natural conditions of land use and human development activities share the same characteristics. Because of this, local governments almost always use watersheds (instead of administrative boundaries) when undertaking environmental or development planning. Therefore, it seems natural to use the boundary of watersheds as the analytical units in this study.

\subsubsection{Creating the road variables}

As a result of these two issues, we developed a three-step procedure to take the digitized road map of the province and turn it into a discrete, pixelspecific measure of the largest road that penetrates any part of each watershed. The first step began with a detailed GIS map of Inner Mongolia. We used this map plus information on elevation and the watershed delineation function in ArcGIS to divide the area of the province into distinct, non-overlapping

4 The ruggedness of the terrain in the Middle grassland region makes our assumption easy to justify. This is not an area of vast open plain. Rather, as discussed in the text, it is an area with (sometimes steep) rolling hills, steep gullies and sharp canyons. Our assumption simply states that if a herder of sheep (or some other person) has a choice of herding sheep (or moving some other resource) down towards the middle flow-line of a watershed, this would be much easier (in most cases) than trying to drive them up over a ridge, across gullies into another watershed. 


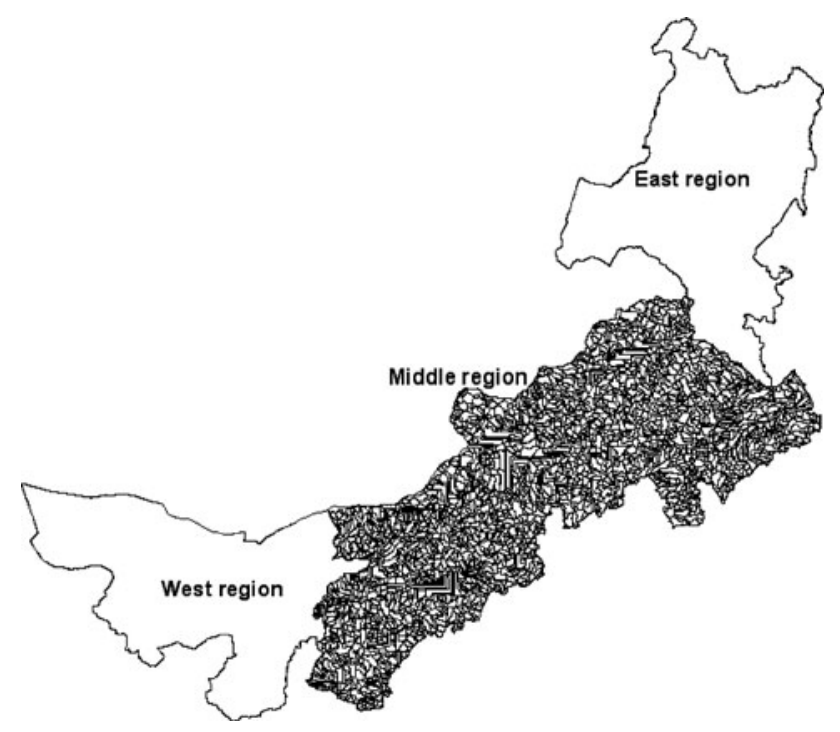

Figure 3. Boundaries of watersheds $(n=5,729)$ in the Middle Grassland Zone of Inner Mongolia.

watersheds. The boundaries of watersheds for the middle zone are shown in figure $3 .^{5}$

In step two, the digitized road map and the digitized watershed map were merged. ${ }^{6}$ Representations of the watershed maps overlaid with the road network are shown in figure 4. This merging was a key step which allowed each watershed to be assigned to one of four categories, according to the size of the largest road that runs through the watershed (see Supplementary appendix 3 online). The four types of roads are: expressways (multilane, controlled access highways); province-level highways (major roads which are typically not controlled access but usually relatively well maintained since the province's highway bureau is charged with their maintenance); other roads (all major roads except expressways and province-level highways); and no roads (watersheds with no major roads - or those with only smaller and village-level roads). After this step every watershed in the province is labeled with one (and only one) of four names: expressway watershed; province-level highway watershed; other road watershed; or no road watershed. If a watershed has an expressway and a province-level highway (and/or other road) inside its boundary it is still, by definition, an expressway watershed.

${ }^{5}$ Because, a priori, there is no optimal number of watersheds, we created two maps, one with 5,729 watersheds and another, more aggregated one, with 2,693. During the analysis phase of the study we used both and compared the results. As it turns out, the nature of the way that we divided the province into watersheds (that is, either 5,729 or 2,693) did not have a significant effect on the fundamental findings of the paper. Therefore, in the paper we only report the results obtained using the larger number of watersheds.

6 The maps were drawn so that a given segment of road could not, simultaneously, be in two watersheds at once. 


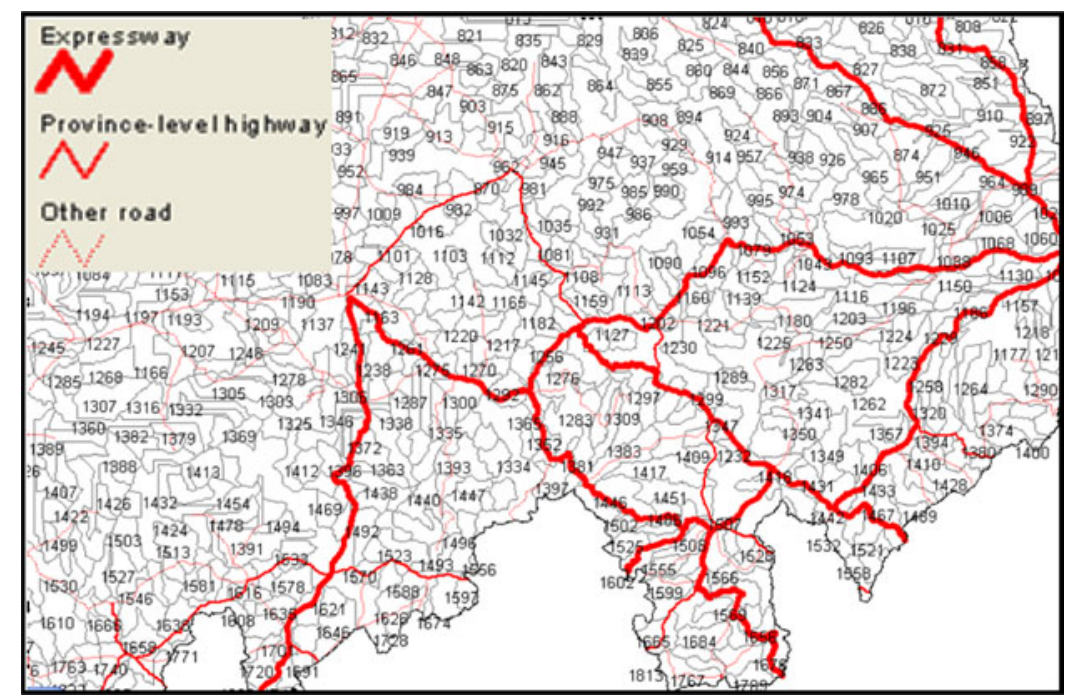

Figure 4. Example of boundaries of watersheds overlaid with the road network in the Middle Grassland Zone of Inner Mongolia in 1995.

The final step assigns all of the pixels in the same way as the watersheds. This, of course, means that each of the 563,296 pixels in the middle zone of Inner Mongolia has one of four designations: expressway pixel, province-level highway pixel, other road pixel, or no road pixel.

\subsubsection{Other control variables}

In addition to information on the grasslands and roads, other data are used to create variables to control for other factors that determine grassland quantity and quality. When looking at the empirical literature on the determinants of grassland cover, we find four broad categories of variables. Ding et al. (2006) and Zheng et al. (2006) and others include a number of geographic and climatic variables. Han et al. (2008), Rozelle et al. (1997), and Williams (2007) include demographic and economic variables. Other authors (e.g., Zhang et al., 2006) include measures of distance from the grassland plots to different features (such as distance to the nearest city). Different authors also consider other factors such as whether or not the pixel is in a protected area (Tilman et al., 2005). In order to make our analysis as consistent as possible with the rest of the literature, we have collected information on four sets of variables: geographic and climatic factors, demographic and economic factors, measures of distance, and other factors. A number of these factors have been consistently found to causally affect grassland degradation in the review paper by Trombulak and Frissell (2000).

To generate the control variables for our analysis, we draw on data and information from a number of different sources. The data for measuring rainfall (measured in mm per year) and temperature (measured in accumulated degrees centigrade per year) are from the CAS data center but were initially collected and organized by the Meteorological Observation Bureau of China from more than 600 national climatic and meteorological data centers. For use in our study, we take the point data from the 15 climate stations 
in Inner Mongolia and interpolate them into surface data using an approach called the thin plate smoothing spline method (Hartkamp et al., 1999). The elevation and terrain slope variables, which measure the nature of the terrain of each county, are generated from China's digital elevation model data set that is part of the basic CAS database. Information on the properties of soil is also part of our set of geographic and climatic variables from the CAS data center. Originally collected by a special nationwide research and documentation project (the Second Round of China's National Soil Survey) organized by the State Council and run by a consortium of universities, research institutes and soils extension centers, we use these data to specify 10 variables: the nitrogen, phosphorous and potassium content of the soil (measured as percentage); available phosphorous and available potassium in the top soil (measured in ppm); soil pH value; soil clay, soil loam and soil sand (denoting the proportion of clay, loam and sand in the soil (measured as percentage); and organic matter in the top soil (measured as percentage). By using a conventional Kriging algorithm (Kravchenko and Bullock, 1999), we are able to interpolate the soil information into surface data to get more disaggregated information on the property of the soil over space for each pixel.

Two demographic and economic variables, population and the level of gross domestic product per $\mathrm{km}^{2}(G D P)$, are included in our modeling work. The demographic data for 1995 and 2000 are from the Population Statistical Yearbook for China's Counties. Information on GDP for each county for 1995 and 2000 is from the Socio-economic Statistical Yearbook for China's Counties (NBSC, 2001). When there are missing data in the yearbook, the information is supplemented by the province's annual statistical yearbook for 1995 and 2000. In order to get pixel-specific measures of the demographic variables we use an approach called the Surface Modeling of Population Distribution framework (Yue et al., 2005; Deng et al., 2008b) to interpolate the data across space (measured as persons $/ \mathrm{km}^{2}$ ). The level of GDP $\left(G D P\right.$ per $\left.\mathrm{km}^{2}\right)$ is also interpolated across space using commonly available GIS algorithms (Doll et al., 2000, 2006; Deng et al., 2008b).

We also created several measures of distance (in $\mathrm{km}$ ), defined separately for each pixel in our sample. The variable, distance to nearest road, measures the distance from each grid cell to the nearest road of any type. Distance to the provincial capital measures the distance (by the shortest road route) from each pixel to Hohhot, Inner Mongolia's provincial capital. We also generated a variable, distance to the nearest urban core, which is the shortest road route from each pixel to the nearest county seat or other major urban center.

Finally, we also obtained data for several other factors. For example, we create a variable, bufferfarmland, to identify if a pixel is surrounded by cultivated area. The idea of including this variable is to hold constant any impact on the grassland that could arise if a pixel of grassland is near an area in which agriculture is being practiced. The variable is created by measuring the percentage of the area that is being cultivated within $10 \mathrm{~km}$ of the pixel of interest. Similarly, we create a variable, bufferforest, to identify if a pixel is surrounded by forested area. Finally, we also include a variable called grassland area in 1995. This variable seeks to hold constant the quality-adjusted quantity of grassland in the initial period of our analysis (measured as QA-Grassland ${ }_{1995}$ ). Table A2 in Supplementary appendix 4 online reports the 
variable name, units, number of observations, mean and standard deviation for all variables used in the paper.

\section{Approach to estimate the multivariate effect of roads on grasslands}

The basic empirical relationship that we are interested in is:

$$
\text { Grassland }_{i, t}=a_{0}+a_{1} \cdot(\text { Access to Roads })_{i, t-j}+e_{i, t}
$$

where Grassland $_{i, t}$ is measured in one of two ways. In one set of regressions, it is the area of the grasslands in pixel $i$ in year $t=2000$. In the other set of regressions it is the change of the area of the grassland in pixel $i$ between 1995 and 2000. This is discussed further below. In addition, because of differences within and across pixels in the quality of grasslands, we replace Grassland with the quality-adjusted measure of grassland area, QA-Grassland.

The explanatory variable of interest, (Access to Roads) $)_{i, t-j}$, is a measure of the nature of the largest road that ran through the watershed which contains pixel $i$ in year $t-j$ (which in our study is $2000-5=1995$ ) and $a_{1}$ is our coefficient of interest. We use a lagged measure of roads (lagging it by 5 years) to help reduce concerns about endogeneity, since changes in grassland cover between 1995 and 2000 (or the level of the grasslands in 2000) should have no direct effect on the road network in 1995.

Since we are interested in the impact of whether there is a road in the watershed (or not) as well as the type of road (expressway vs. province-level highway vs. other road), we define Access to Roads $s_{i, t-j}$ in four different ways. In model 1.1, we include in our sample only the expressway and province-

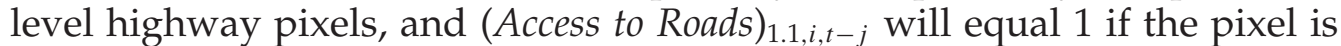
an expressway pixel and 0 if the pixel is a province-level highway pixel. Note, the other road pixels and no road pixels are excluded from the analysis when we use (Access to Roads) $)_{1.1, i, t-j}$. In the estimation of model 1.1, $a_{1.1}$ will measure the effect on the grassland area of changing a highway system from a province-level highway to an expressway.

In model 1.2, we include in our sample only the expressway, provincelevel and other road pixels, and Access to Roads $s_{1,2, i, t-j}$ will equal 1 if the pixel is either an expressway pixel or a province-level highway pixel and 0 if the pixel is a 'other road pixel'. In the estimation of model 1.2, $a_{1.2}$ will measure the effect on the grassland area of changing a highway system from some other road to either a province-level highway or to an expressway. The roadless pixels are dropped from the analysis when we work with model 1.2.

In models 1.3 and 1.4 we use the full sample (that is all of the pixels in the middle zone of Inner Mongolia). The empirical exercise in model 1.3 is like that of model 1.2, except we set Access to Roads ${ }_{1.3, i, t-j}=0$ when the pixels are either other road pixels or no road pixels. In that way, the interpretation of $a_{1.3}$ becomes the effect on the grassland area of changing a highway system from some other road to either a province-level highway or to an expressway, or of building a province-level highway or expressway into a previously roadless watershed. In model 1.4, we set Access to $\operatorname{Road}_{1.4, i, t-j}=1$ if there is any type of road in the watershed, and set it to 0 if there is no road in the watershed. The interpretation of $a_{1.4}$ becomes the effect on the 
grassland area of building any type of road into a previously roadless watershed. Table 1 summarizes the different 'experiments' that are conducted by estimating models 1.1-1.4.

The estimation of $a_{1}$ using equation (2), of course, is problematic for several reasons. Pixels in watersheds with expressways are likely to differ from those in watersheds without any roads (or with only minor roads) in many ways. They may have easier topography and more productive soils along with a number of unobserved locational advantages, since richer areas (or areas with more development potential) are more likely to attract investment in roads. Hence, applying OLS to equation (2) is unlikely to give unbiased treatment effects estimates of what happens to the grassland cover when a previously roadless watershed has new roads introduced (or existing roads upgraded). Indeed, as discussed above, previous work (Zhang et al., 2006) suggests many other factors that might affect grassland area and since some are likely to be correlated with both grassland area and access to roads, we can reduce omitted variable bias by controlling for as many variables as possible. This gives the model:

$$
\text { Grassland }_{i, t}=a_{0}+a_{1} \cdot(\text { Access to Roads })_{i, t-j}+a_{2} Z_{i}+e_{i, t}
$$

Where, in addition to the variables and parameters in equation (2), equation (3) includes the matrix $Z$. In our analysis $Z$ includes 14 measures of geographic and climatic variables (elevation, terrain slope, nitrogen, phosphorous, potassium, available phosphorous, available potassium, soil $\mathrm{pH}$ value, soil clay, soil loam, soil sand, organic matter, temperature and rainfall); two measures of demographic and economic variables (population and GDP); three measures of distance variables (distance to the nearest road, distance to the provincial capital and distance to the nearest urban core); and two other variables (bufferfarmland and bufferforest). In versions of the equations in which the dependent variable is the change in the grassland (from 1995 to 2000), we also include an additional variable that holds constant the level of the grassland in 1995 (Grassland area in 1995). Since most of the 22 variables in $Z$ - all except population, GDP, bufferarea10 and distance to the nearest urban core - only vary across space, we only include an $i$ subscript on $Z$.

\subsection{Matching methodology}

As in the case of our OLS models (in equations (2) and (3)), the matching method is another way to examine the impact of a treatment (in our context, existence of particular types of roads) on an outcome (in our case, grassland) when selection takes place on observable characteristics (Rosenbaum and Rubin, 1983; Dehejia and Wahba, 2002). Estimating the effect of roads on grassland cover without bias using the matching method assumes that the outcome in the base state (grassland if the pixel was not in a watershed with a particular type of road) is independent of the treatment, conditional on observed covariates $Z$. In other words, for pixels within subgroups defined by $Z$, being located in a watershed with roads is unrelated to what the grassland cover would be if the pixel were not in a watershed with roads. This is the so-called Conditional Independence Assumption. If this assumption holds, we can say that, given the observable covariates, the grassland cover 
Table 1. Definition of Access to Roads variables

\begin{tabular}{|c|c|c|c|c|c|c|c|c|}
\hline & \multicolumn{4}{|c|}{$\begin{array}{l}\text { Treated: the largest type of road that goes } \\
\text { through the watershed is }{ }^{a} \text { : }\end{array}$} & \multicolumn{4}{|c|}{$\begin{array}{l}\text { Control: the largest type of road that goes } \\
\text { through the watershed is: }\end{array}$} \\
\hline & Expressway & $\begin{array}{l}\text { Province-level } \\
\text { highway }\end{array}$ & $\begin{array}{l}\text { Other } \\
\text { roads }\end{array}$ & $\begin{array}{l}\text { No } \\
\text { road }\end{array}$ & Expressway & $\begin{array}{l}\text { Province-level } \\
\text { highway }\end{array}$ & $\begin{array}{l}\text { Other } \\
\text { roads }\end{array}$ & $\begin{array}{l}\text { No } \\
\text { road }\end{array}$ \\
\hline $\begin{array}{l}\text { Expressway vs. province-level highway } \\
\text { (Access to Roads) }{ }_{1.1}\end{array}$ & $\mathrm{Y}^{b}$ & & & & & $\mathrm{Y}$ & & \\
\hline $\begin{array}{l}\text { Expressway and/or province-level } \\
\text { highway vs. other roads } \\
\text { (Access to Roads) })_{1.2}\end{array}$ & $\mathrm{Y}$ & $\mathrm{Y}$ & & & & & $\mathrm{Y}$ & \\
\hline $\begin{array}{l}\text { Expressway and/or province-level } \\
\text { highway vs. other roads or } \\
\text { no roads (Access to Roads) })_{13}\end{array}$ & $\mathrm{Y}$ & $\mathrm{Y}$ & & & & & $\mathrm{Y}$ & $\mathrm{Y}$ \\
\hline $\begin{array}{l}\text { Expressway and/or province-level } \\
\text { highway and/or other roads } \\
\text { vs. no roads (Access to Roads) } 1.4\end{array}$ & $\mathrm{Y}$ & $\mathrm{Y}$ & $\mathrm{Y}$ & & & & & $\mathrm{Y}$ \\
\hline
\end{tabular}

${ }^{a}$ If the largest type of road that goes through the watershed is expressway, the watershed may also contain province-level highway or other roads. Likewise, if the largest type of road is province-level highway, it may also include other roads.

${ }^{b} Y$ denotes that this largest type of road goes through the watershed. 
of the control pixels is what the grassland cover of the treated pixels would have been had the road (or had the larger road) not penetrated into the watershed of the treatment pixel.

Unlike OLS, however, matching works by finding a control pixel that is very similar to the treatment pixel by conditioning on $Z$ variables nonparametrically rather than linearly (Black and Smith, 2004). To take advantage of the matching method, we follow the recent literature and match every treated pixel with a control pixel using the Covariate Matching estimator developed by Abadie and Imbens (2006). With Covariate Matching we estimate the average treatment effect on the change in grassland cover by comparing outcomes between treated observations (pixels in a watershed with a specific type of road), and control observations (pixels in a watershed without the specific type of road). In our analysis, we choose to match the two nearest neighbors with the same (similar) covariates $(Z)$, where the variables in $Z$ are the same as in equation (3). Within this set of pixels, we can then directly estimate $E\left(Y_{i 1} \mid T_{i}=1, Z_{i}\right)$ and $E\left(Y_{i 0} \mid T_{i}=1, Z_{i}\right)$. This approach means that once we have a matched sample, we compare the grassland of the treated pixel with the grassland of the control pixel. One additional advantage of Covariate Matching is that it allows us to correct for the bias caused by the matching discrepancy. To minimize geographic mismatch, we enforce exact matching by prefecture; that is, only pixels from the same prefecture are allowed to be matched. The exact matching helps control for unobserved heterogeneity at the prefecture level (e.g., policy environment). With covariate matching, we report the results using the Mahalanobis metric weighting scheme.

Using the method of matching also has the additional advantage of alleviating spatial issues. The basic unit of observation in our study is the $1 \mathrm{~km}^{2}$ pixel, of which there are 563,296 in the middle zone of Inner Mongolia. When using such data there is a high correlation in grassland cover between neighboring pixels (as well as lesser - but still statistically significant - correlation in the residuals of the OLS estimates of equation (3). ${ }^{7}$

When estimating the relationship between access to roads and the grassland this spatial autocorrelation can lead to inefficiency and invalid hypothesis testing procedures (Anselin, 2001). Matching methods should eliminate most of the spatial autocorrelation because every treated pixel is matched with a control pixel from a different watershed. Except for the extreme case where the two matched pixels share a common watershed boundary, the pixels are unlikely to be adjacent neighbors. ${ }^{8}$

7 The Moran $I$ statistic is more than 0.50 for the dependent variable and 0.30 for the residuals. Intuitively, this statistic is equivalent to the slope coefficient of a linear regression of the weighted average value of grassland cover (residuals) for the pixels surrounding the $i$ th pixel on the grassland cover (residual) in pixel $i$.

8 Our second strategy to deal with the spatial issues is to also estimate the model at the watershed level (in addition to estimating the model at the pixel level). Aggregating over neighboring pixels that have highly similar information may not make much difference, depending on how great the variability in grassland cover is within the watershed. In other words, the smaller the spatial scale at which the 
3.2. Two definitions of the dependent variable: grassland and change in grassland As discussed above, we have two dependent variables of interest. Many studies of roads and grassland degradation use cross-sectional data on grassland area. However, such a cross-section may merely illustrate the correlation between where roads and grasslands are (i.e., which areas are more remote and which areas are more developed). To estimate the causal impact of roads on grasslands, one would want to look at the changes in grassland. Fortunately, as discussed above, we have two years of land use data for each pixel in Inner Mongolia. Therefore, in the rest of our analysis, we report estimates for all of the models using two dependent variables - grassland area in 2000, and the change in the grassland area between 1995 and 2000.

\subsection{Accounting for heterogeneous effects}

As discussed above, across pixels and within pixels the quality of grassland varies. In fact, although total grassland cover and quality-adjusted grassland cover decline between 1995 and 2000, the same is not necessarily true for the rates of change for Dense, Moderate and Sparse grasslands change. While the area of Dense grassland did fall (as did quality-adjusted grassland), moderate canopy grassland showed almost no change. At the same time, Sparse grassland actually rises over time. Because of these differences among types of grassland, in the analysis we look separately at the effect of access to roads on quality-adjusted, Dense, Moderate and Sparse grasslands.

\section{Results}

If we were to use a traditional OLS approach and control for covariates (that is, if we estimated our model using equation (3) to analyze the effect of roads using an aggregate measure of the grassland resource (QA-Grassland), the results would suggest that roads lead to grassland degradation (table 2, columns 1 and 6). ${ }^{9}$ In fact, regardless of our measure of the access to roads (Access to Roads 1.1, 1.2, 1.3 and 1.4), after holding constant the effect of 21 other control variables, the level of the grassland in 2000 is shown to be lower in areas with roads or in areas in which there are larger or more improved roads (column 1, rows 1-4). The $t$-ratios associated with the Access to Roads variable in all of the equations suggest that the estimated effects are significantly different from zero.

Roads are also shown to be associated with grassland degradation when we measure the degradation effect as the change in the grassland between 1995 and 2000 (that is: QA-Grassland 2000 - QA-Grassland ${ }_{1995}$ - table 2, column 6). As in the case of the regression when using the 2000 level of the grassland, regardless of the way we measure access to roads (1.1, 1.2, 1.3 or 1.4), the sign on the Access to Roads variable is negative (rows 1-4). The

process operates, the less accurate will be the aggregate as an estimate for the dependent variable (Anselin, 2001).

9 The signs and levels of significance of estimated coefficients of most control variables are consistent with our expectations (results not reported but available from authors upon request). For example, when rainfall level is higher, there is more grassland of high quality. When the temperature is higher, there is less grassland of high quality. 
Table 2. Pixel-specific impacts of roads (1995) on the level of grassland (2000) and the changes in grassland (between 1995 and 2000) for the Middle Grassland Zone of Inner Mongolia, China, based on the OLS estimation with covariates ${ }^{a}$

\begin{tabular}{|c|c|c|c|c|c|c|c|c|c|c|c|c|}
\hline & \multicolumn{5}{|c|}{ Dependent variable: level } & \multicolumn{5}{|c|}{ Dependent variable: change } & \multirow[b]{2}{*}{$\begin{array}{l}N \\
\text { treated }\end{array}$} & \multirow[b]{2}{*}{$\begin{array}{l}N \text { available } \\
\text { controls }\end{array}$} \\
\hline & $\begin{array}{l}\text { QA- } \\
\text { grassland }^{b}\end{array}$ & $\begin{array}{l}\text { Dense } \\
\text { grassland }\end{array}$ & $\begin{array}{l}\text { Moderate } \\
\text { grassland }\end{array}$ & $\begin{array}{l}\text { Sparse } \\
\text { grassland }\end{array}$ & $\begin{array}{l}\text { Other } \\
\text { land }\end{array}$ & $\begin{array}{l}\text { QA- } \\
\text { grassland }^{a}\end{array}$ & $\begin{array}{l}\text { Dense } \\
\text { grassland }\end{array}$ & $\begin{array}{l}\text { Moderate } \\
\text { grassland }\end{array}$ & $\begin{array}{l}\text { Sparse } \\
\text { grassland }\end{array}$ & $\begin{array}{l}\text { Other } \\
\text { land }\end{array}$ & & \\
\hline $\begin{array}{l}\text { (Access to } \\
\text { Roads) }\end{array}$ & $\begin{array}{l}-1.16 \\
(5.43)^{* * *}\end{array}$ & $\begin{array}{l}-3.58 \\
(9.44)^{* * *}\end{array}$ & $\begin{array}{c}2.28 \\
(13.49)^{* *}\end{array}$ & $\begin{array}{l}1.75 \\
(8.59)^{* * * *}\end{array}$ & & $\begin{array}{l}-1.21 \\
(14.63)^{* * *}\end{array}$ & $\begin{array}{l}-2.84 \\
(20.61)^{* * *}\end{array}$ & $\begin{array}{l}-2.71 \\
(18.15)^{* * *}\end{array}$ & $\begin{array}{l}0.25 \\
(2.11)^{* *}\end{array}$ & $\begin{array}{l}-1.11 \\
(9.16)^{* * *}\end{array}$ & 100,192 & 49,318 \\
\hline (Access to & -1.94 & -2.50 & 1.64 & 1.42 & -0.95 & -0.22 & -1.10 & 2.02 & 0.87 & -0.37 & 149,510 & 212,459 \\
\hline Roads) $)_{1.2}$ & $(23.76)^{* * *}$ & $(18.85)^{* * *}$ & $(3.66)^{* * *}$ & $(17.79)^{* *}$ & $(8.12)^{* * *}$ & $(3.67)^{* * *}$ & $(9.89)^{* * *}$ & $(17.17)^{* * *}$ & $(9.98)^{* * *}$ & $(4.87)^{* * *}$ & & \\
\hline $\begin{array}{l}\text { (Access to } \\
\text { Roads) }\end{array}$ & $\begin{array}{l}-2.97 \\
(6.06)^{* * *}\end{array}$ & $\begin{array}{l}-0.53 \\
(5.54)^{* * *}\end{array}$ & $\begin{array}{c}0.04 \\
(0.01)\end{array}$ & $\begin{array}{c}1.08 \\
(23.02)^{* * * *}\end{array}$ & $\begin{array}{l}-0.91 \\
(8.54)^{* * *}\end{array}$ & $\begin{array}{c}-0.04 \\
(0.83)\end{array}$ & $\begin{array}{l}-0.66 \\
(6.96)^{* * *}\end{array}$ & $\begin{array}{c}1.65 \\
(16.07)^{* * *}\end{array}$ & $\begin{array}{c}1.00 \\
(12.75)^{* * *}\end{array}$ & $\begin{array}{l}-0.30 \\
(4.39)^{* * *}\end{array}$ & 149,510 & 413,786 \\
\hline (Access to & -0.41 & -0.29 & 1.60 & 0.01 & -0.06 & -0.11 & -0.80 & 1.65 & 0.72 & -0.07 & 361,969 & 201,327 \\
\hline Roads) $)_{1.4}$ & $(1.92)^{* *}$ & $(0.77)$ & $(4.11)^{* * *}$ & $(1.04)$ & $(0.60)$ & $(2.06)^{* *}$ & $(8.27)^{* * *}$ & $(15.85)^{* * *}$ & $(9.03)^{* * * *}$ & (1.07) & & \\
\hline
\end{tabular}

Notes: Results of $t$-tests for the difference in the mean change between treatment and control groups are reported with asterisks. *denotes significance level at $10 \%$; ${ }^{* *}$ denotes significance level at $5 \%$; ${ }^{* * *}$ denotes significance level at $1 \%$.

${ }^{a}$ In this table we report only the coefficients for the variable of interest (access to roads). If the reader is interested in examining the full regressions (with all of the coefficients and goodness of fit statistics), please see tables A3 - A6 in Supplementary appendix 5 online. ${ }^{b}$ Quality-adjusted grassland area is calculated as $0.75 \times($ Dense grassland area $)+0.35 \times($ Moderate grassland area $)+0.125 \times$ (Sparse grassland area). 
coefficient is statistically significant in three of the four versions of the regression (all except row 3 for Access to $\operatorname{Road}_{1.3}$ ). According to this traditional approach of analyzing the effect of roads on grasslands, roads lead to grasslands degradation. In all of the eight regressions (using the two measures of the dependent variable and the four measures of the independent variable of interest), the sign on the Access to Roads variable is negative; it is statistically significant in seven of the cases.

The importance of using a better strategy to control for the covariates by using a Covariate Matching approach is evident when comparing the results from table 2, columns 1 and 6 (the results from the OLS estimation) and the results from table 3, columns 1 and 5 (the results from the Covariate Matching approach). This is especially true when we look at the results of the Covariate Matching approach that seek to estimate the effect of roads in 1995 on the level of the aggregate grasslands in 2000 (QA-Grasslands ${ }_{2000}$ ). The signs on the Access to Roads variable (1.1, 1.2 and 1.3) actually change (from negative to positive), although the $t$-ratios are small in all of the cases. Only in the final regression (measuring the effect of Access to Roads s.4 $_{1.4}$ in 1995 on QA-Grasslands ${ }_{2000}$ ) is the sign negative and statistically significant. The magnitude of the coefficient, however, is much smaller in table 3 (column 1, row 4) than in table 2 (column 1, row 4). Moreover, although the signs on all four of the coefficients of the Access to Road variable in the set of Covariate Matching regressions that use the change in the grasslands between 1995 and 2000 are still negative, only two of the four are statistically significant. Therefore, our degree of confidence in the claim that our estimates demonstrate that roads negatively affect grasslands must necessarily be lower when we move from a traditional OLS approach to one using Covariate Matching that is better suitable for analyzing the treatment effect.

\subsection{Roads and the grassland: when grassland quality is considered}

If the above exercises suggest that using Covariate Matching is important, the results using our measures of grasslands disaggregated by quality (regardless of whether or not we used OLS or Covariate Matching) demonstrate that it is even more important to estimate the regressions separately with measures of Dense grassland cover; Moderate grassland cover and Sparse grassland cover as the dependent variables (tables 2 and 3, columns 2-4 and columns 6-8). Specifically, when using OLS estimation with covariates (table 2), we can see how our results change completely when we estimate the effect of Access to Roads on the level of Dense grassland cover (column 2) compared to the case when we estimate the effect of Access to Roads on the level of Sparse grassland cover (column 4). The same is true when examining the difference between the effects of Access to Roads on the change in Dense grassland cover compared with the change in Sparse grassland cover (columns 6 and 8). In the case of all Access to Roads measures, the sign on the coefficient is negative (and significant in seven of eight regressions) when looking at the effect of roads on high quality grassland (Dense grassland). In contrast, in the case of all Access to Roads measures, the sign on the coefficient is positive (and also significant in seven of the eight regressions) when looking at the effect of roads on low quality grassland 
Table 3. Pixel-specific impacts of roads (1995) on the level of grassland (2000) and the changes in grassland (between 1995 and 2000) for the Middle Grassland Zone of Inner Mongolia, China, based on Covariate Matching estimation with covariates

\begin{tabular}{|c|c|c|c|c|c|c|c|c|c|c|}
\hline & \multicolumn{4}{|c|}{ Dependent variable: level } & \multicolumn{4}{|c|}{ Dependent variable: change } & \multirow[b]{2}{*}{$N$ treated } & \multirow[b]{2}{*}{$\begin{array}{l}N \text { available } \\
\text { controls }\end{array}$} \\
\hline & $Q A-$ Grassland $^{a}$ & $\begin{array}{l}\text { Dense } \\
\text { grassland }\end{array}$ & $\begin{array}{l}\text { Moderate } \\
\text { grassland }\end{array}$ & $\begin{array}{l}\text { Sparse } \\
\text { grassland }\end{array}$ & QA-Grassland ${ }^{a}$ & $\begin{array}{l}\text { Dense } \\
\text { grassland }\end{array}$ & $\begin{array}{l}\text { Moderate } \\
\text { grassland }\end{array}$ & $\begin{array}{l}\text { Sparse } \\
\text { grassland }\end{array}$ & & \\
\hline (Access to & 0.59 & -0.31 & 1.89 & 0.53 & -0.30 & -0.56 & 1.73 & 1.36 & 149,510 & 212,459 \\
\hline Roads) $)_{1.2}$ & $(0.13)$ & $(1.79)$ & $(3.09)^{* * *}$ & $(10.04)^{* * *}$ & $(1.41)$ & $(1.23)$ & $(3.54)^{* * *}$ & $(2.28)^{* *}$ & & \\
\hline (Access to & -0.18 & -0.70 & 0.81 & 0.47 & -0.28 & -0.95 & 1.14 & 3.07 & 361,969 & 201,327 \\
\hline Roads) 1.4 & $(2.85)^{* * *}$ & $(2.97)^{* * *}$ & $(2.92)^{* * *}$ & $(0.03)$ & $(1.35)$ & $(2.38)^{* * *}$ & $(2.05)^{* *}$ & $(6.58)^{* * *}$ & & \\
\hline
\end{tabular}

Note: Results of $t$-tests for the difference in the mean change between treatment and control groups are reported as asterisks: ${ }^{*}$ significant at $10 \%$; ** significant at $5 \% ; * * *$ significant at $1 \%$.

${ }^{a}$ Quality-adjusted grassland area is calculated as $0.75 \times($ Dense grassland area $)+0.35 \times($ Moderate grassland area $)+0.125 \times$ (Sparse grassland area). 
(Sparse grassland). In other words, our results suggest that roads are leading to the degradation of Dense grassland cover while at the same time (in other places) roads are associated with the restoration of Sparse grassland cover.

The exact same story is found when examining the difference in the effect of roads on Dense and Sparse grassland cover using Covariate Matching (table 2, columns 2 and 4,6 and 8). In all of the regressions that examine how the Access to Roads variables affects Dense grassland cover, the signs are negative (and significant in five of the eight regressions). The findings are the exact opposite in the case of low quality grasslands. In all of the regressions that examine how the Access to Roads variables affects Sparse grassland cover, the signs are positive (and significant in six of the eight regressions). Clearly, whether we use OLS or Covariate Matching, we find sharply varying effects of roads on the grasslands, depending on the quality of the resource. ${ }^{10}$

Does this necessarily mean that roads are good for Sparse grassland land cover? In fact, because of the possibility that there are shifts of grassland among the three types of grassland due to Access to Roads, the estimated parameters for Access to Roads in the three equations may include two parts. First, it could be that roads are generating more Sparse grassland cover or more Moderate grassland cover. Second, and less inherently positive, it could be that roads are degrading Dense and Moderate grassland cover and this is why Sparse grassland cover is rising. Unfortunately, we are not able to separate the different nature of the shifts of land among three grasslands and between grassland and other land, given the data we have. The reader needs to remember this caveat when interpreting the results.

\section{Conclusion and discussion}

In this paper we have sought to estimate the impacts of roads on grassland in the middle region of Inner Mongolia. However, our paper goes further and shows the importance of the choice of methodology and modeling in analyzing the estimated effects. In particular, we found that using Covariate Matching was important in reducing potential bias, due to the non-parametric nature of the matching estimation and the correction of matching discrepancies in the matching procedure, while the OLS estimates produced a set of results that were fairly convincing in showing the negative effect of roads on the overall nature of the grassland resources.

Above all, however, we found that it was even more important to disaggregate the quality of resource when estimating the impact on roads. Regardless of our estimation approach, we found that roads appear to have a negative and significant effect on grasslands degradation in areas where the resource is high in quality (that is, in regressions with Dense grassland cover as the dependent variable). In contrast, roads lead to higher levels

${ }^{10}$ We also used a Propensity Score Matching (PSM) estimator as a robustness check (results not reported, to save space). The results from PSM are largely consistent with those from Covariate Matching, suggesting robust findings from our choice of matching estimators. 
of the grassland when resources are relatively lower quality. While this could be shifts from Dense and Moderate grassland that is deteriorating, it might also be a sign that restoration is occurring. Hence, accounting for the heterogeneous nature of the resource can completely change the estimated relationship and could make a big difference in any policy analysis that would rely on the estimates.

So why might we see these polar results in areas with Dense grassland cover and Sparse grassland cover? While it is beyond the scope of this paper to identify the exact mechanism, logically one could imagine that these results are plausible. When roads penetrate into (or are improved in) areas with high quality grasslands, it may intensify efforts to exploit the resource which is worth exploiting, given its high quality. This is indeed what may be happening in the areas with significant amounts of Dense grassland cover. According to provincial level statistics (MOA, 2009), mutton production rose by more than 10 times between the 1980s and 2008. However, when roads enter into areas with low quality (previously degraded?) grass, assuming that there is restoration at work, it is possible that roads can be used as an avenue of escape (and allow people to move out of the grassland areas for working and living). Two distinctive trends in Inner Mongolia would support such an interpretation. First, while in the 1980s there was almost no dairy production in Inner Mongolia, by 2008 there were significantly more dairy cows than sheep (MOA, 2009). Dairy cows in Inner Mongolia are almost all raised in penned environments and would have distinctly less impact on the grassland. Second, migration across China, including from Inner Mongolia, has risen rapidly during the 1990s and 2000s (Huang et al., 2009). It is also possible that new roads into such areas would allow other non-grass-based enterprises/industries to enter into the grasslands and divert the attention from grass-based activities to non-grass-based activities. Further research is needed to more fully understand the behavioral dynamics underlying our econometric findings.

In the same vein, it is important to bear in mind that decline in grassland in the areas with rich and high quality grassland on the one hand, and improvement in the sparsely covered grassland on the other, cannot be treated as canceling each other out. The two may have fairly distinct implications for the environment and ecology. Hence, future work on the value of the ecosystem services that are destroyed and/or created needs to proceed, work that would allow policy makers to better judge and measure the full impact of roads.

\section{Supplementary materials}

The supplementary materials referred to in this article can be found online at journals.cambridge.org/ede.

\section{References}

Abadie, A. and G.W. Imbens (2006), 'Large sample properties of matching estimators for average treatment effects', Econometrica 74(1): 235-267.

Akiyama, T. and K. Kawamura (2007), 'Grassland degradation in China: methods of monitoring, management and restoration', Grassland Science 53(1): 1-17. 
Andersen, L.E., C.W.J. Granger, E.J. Reis, D. Weinhold, and S. Wunder (2002), The Dynamics of Deforestation and Economic Growth in the Brazilian Amazon, New York: Cambridge University Press.

Anselin, L. (2001), 'Spatial effects in econometric practice in environmental and resource economics', American Journal of Agricultural Economics 83(3): 705-710.

Black, D.A. and J.A. Smith (2004), 'How robust is the evidence on the effects of college quality? Evidence from matching', Journal of Econometrics 121(1-2): 99-124.

China Agricultural Zoning Committee (1989), Agricultural Natural Resources and Agricultural Zoning in China, Beijing: China Agricultural Press.

Chomitz, K.M. and D.A. Gray (1996), 'Roads, land use, and deforestation: a spatial model applied to Belize', The World Bank Economic Review 10(3): 487-512.

Conant, R.T., K. Paustian, and E.T. Elliott (2001), 'Grassland management and conversion into grassland: effects on soil carbon', Ecological Applications 11(2): 343-355.

Cropper, M., J. Puri, and C. Griffiths (2001), 'Predicting the location of deforestation: the role of roads and protected areas in North Thailand', Land Economics 77(2): 172-186.

Dehejia, R.H. and S. Wahba (2002), 'Propensity score-matching methods for nonexperimental causal studies', Review of Economics and Statistics 84(1): 151-161.

Deininger, K. and B. Minten (2002), 'Determinants of deforestation and the economics of protection: an application to Mexico', American Journal of Agricultural Economics 84(4): 943-960.

Deng, X.Z., J. Huang, S. Rozelle, and E. Uchida (2006), 'Cultivated land conversion and potential agricultural productivity in China', Land Use Policy 23(4): 372-384.

Deng, X. Z, J. Huang, S. Rozelle, and E. Uchida (2008a), 'Growth, population and industrialization, and urban land expansion of China', Journal of Urban Economics 63(1): 96-115.

Deng, X.Z., H. Su, and J.Y. Zhan (2008b), 'Integration of multiple data sources to simulate the dynamics of land systems', Sensors 8: 620-634.

Ding, Y., J. Niu, and C. Yang (2006), 'Plant community succession of degradation and desertification in sandy grassland', Chinese Journal of Ecology 25(9): 1044-1051 [in Chinese].

Doll, C.N.H., J.P. Muller, and C.D. Elvidge (2000), 'Night-time imagery as a tool for global mapping of socio-economic parameters and greenhouse gas emissions', AMBIO 29(3): 157-162.

Doll, C.N.H., J.P. Muller, and J.G. Morley (2006), 'Mapping regional economic activity from night-time light satellite imagery', Ecological Economics 57(1): 75-92.

Forman, R.T.T. (2000), 'Estimate of the area affected ecologically by the road system in the United States', Conservation Biology 14(1): 31-35.

Forman, R.T.T., B. Reineking, and A.M. Hersperger (2002), 'Road traffic and nearby grassland bird patterns in a suburbanizing landscape', Environmental Management 29(6): 782-800.

Gao, Q., Y. Wan, Y. Li, W. Sheng, W. Jiangcun, B. Wang, and W. Li (2007), 'Trends of grassland NPP and its response to human activity in Northern Tibet', Acta Ecologica Sinica 27(11): 4612-4619 [in Chinese].

Gong, L.S., Y. Harazono, T. Oikawa, H.L. Zhao, Z. Ying He, and X.L. Chang (2000), 'Grassland desertification by grazing and the resulting micrometeorological changes in Inner Mongolia', Agricultural and Forest Meteorology 102(2-3): 125-137.

Han, J.G., Y.J. Zhang, C.J. Wang, W.M. Bai, Y.R. Wang, G.D. Han, and L.H. Li (2008), 'Rangeland degradation and restoration management in China', Rangeland Journal 30(2): 233-239. 
Hartkamp, A.D., K. De Beurs, A. Stein, and J.W. White (1999), 'Interpolation techniques for climate variables', NRG-GIS Series 99-01, CIMMYT, Mexico City.

Huang, J.K., L.X. Zhang, X.F. Li, and S. Rozelle (2009). 'China's labor transition and the future of China's rural wages and employment', Center for Chinese Agricultural Policy Working Paper, CCAP, Chinese Academy of Sciences, Beijing.

Jenkins, G.J., J.J. Ephraums, and J.T. Houghton (1990), Climate Change: The IPCC Scientific Assessment, New York: Cambridge University Press.

Kravchenko, A. and D.G. Bullock (1999), 'A comparative study of interpolation methods for mapping soil properties', Journal of Agronomy 91: 393-400.

Liu, G.D., D.L. Michalk, C.J. Bai, D.G. Yu, and Z.Q. Chen (2008), 'Grassland development in tropical and subtropical southern China', Rangeland Journal 30(2): 255-270.

Liu, J.Y., M.L. Liu, X.Z. Deng, D.F. Zhuang, and D. Luo (2002), 'The land-use and land-cover change database and its relative studies in China', Journal of Geographical Sciences 12(3): 275-282.

Liu, J.Y., M.L. Liu, D.F. Zhuang, Z.X. Zhang, and X. Z. Deng (2003), 'Study on spatial pattern of land-use change in China during 1995-2000', Science in China Series D Earth Sciences 46(4): 373-384.

Magurran, A.E. (2004), Measuring Biological Diversity, Malden, MA: WileyBlackwell.

Mertens, B. and E.F. Lambin (1997), 'Spatial modelling of deforestation in southern Cameroon - spatial disaggregation of diverse deforestation processes', Applied Geography 17(2): 143-162.

MOA (Ministry of Agriculture) (2009), Sixty Years of New China's Agriculture, Beijing: China Agriculture Press.

NBSC (National Bureau of Statistics China) (2001), China Statistical Yearbook, Beijing: China Statistical Publishing House.

Pfaff, A.S.P. (1999), 'What drives deforestation in the Brazilian Amazon? Evidence from satellite and socioeconomic data', Journal of Environmental Economics and Management 37(1): 26-43.

Rosenbaum, P.R. and D.B. Rubin (1983), 'The central role of the propensity score in observational studies for causal effects', Biometrika 70(1): 41-55.

Rozelle, S., J. Huang, and L. Zhang (1997), 'Poverty, population and environmental degradation in China', Food Policy 22(3): 229-251.

Smil, V. (1993), China's Environmental Crisis: An Inquiry into the Limits of National Development, New York: M.E. Sharpe.

Tilman, D. and J.A. Downing (1994), 'Biodiversity and stability in grasslands', Nature 367(6461): 363-365.

Tilman, D., S. Polasky, and C. Lehman (2005), 'Diversity, productivity and temporal stability in the economies of humans and nature', Journal of Environmental Economics and Management 49(3): 405-426.

Trombulak, S.C. and C.A. Frissell (2000), 'Review of ecological effects of roads on terrestrial and aquatic communities', Conservation Biology 14(1): 18-30.

White, R.P., S. Murray, and M. Rohweder (2000), Pilot Analysis of Global Ecosystems: Grassland Ecosystems, Washington, DC: World Resources Institute.

Williams, N.S.G. (2007), 'Environmental, landscape and social predictors of native grassland loss in western Victoria, Australia', Biological Conservation 137(2): 308-318.

Williams, N.S.G., J.W. Morgan, M.A. McCarthy, and M.J. McDonnell (2006), 'Local extinction of grassland plants: the landscape matrix is more important than patch attributes', Ecology 87(12): 3000-3006. 
Williams, N.S.G., J.W. Morgan, M.J. McDonnell, and M.A. McCarthy (2005), 'Plant traits and local extinctions in natural grasslands along an urban-rural gradient', Journal of Ecology 93(6): 1203-1213.

$\mathrm{Wu}, \mathrm{B}$. and L.J. Ci (2002), 'Landscape change and desertification development in the Mu Us Sandland, Northern China', Journal of Arid Environments 50(3): 429-444.

Yue, T.X., Y.A. Wang, J.Y. Liu, S.P. Chen, D.S. Qiu, X.Z. Deng, M.L. Liu, Y.Z. Tian, and B.P. Su (2005), 'Surface modeling of human population distribution in China', Ecological Modelling 181(4): 461-478.

Zhang, Y., L. Liu, W. Bai, Z. Shen, J. Yan, M. Ding, S. Li, and D. Zheng (2006), 'Grassland degradation in the source region of the Yellow River', Acta Geographica Sinica 61(1): 3-14 [in Chinese].

Zhang, Y.L., J.Z. Yan, L.S. Liu, W.Q. Bai, C.S. Li, and D. Zheng (2002), ' Impact of Qinghai-Xizang Highway on land use and landscape pattern change: from Golmud to Tanggulashan Pass', Acta Geographica Sinica 57(3): 253-266 [in Chinese].

Zheng, Y.R., Z.X. Xie, C. Robert, L.H. Jiang, and H. Shimizu (2006), 'Did climate drive ecosystem change and induce desertification in Otindag sandy land, China over the past 40 years?', Journal of Arid Environments 64(3): 523-541. 